Cad. Est. Ling., Campinas, 46(1):53-69, Jan./Jun. 2004

\title{
ANÁLISE QUANTITATIVA DA TENSIVIDADE NO CONTEÚDO VERBAL TENDO EM VISTA O ESTUDO DA EXPRESSÃO DA EMOÇÃO NA FALA E O MODELAMENTO PROSÓDICO
}

\author{
ANA CRISTINA FRICKE MATTE* \\ (FALE/UFMG)
}

\begin{abstract}
In order to support with semiotic information the research in the field of phonostylistics, we propose a formula that allows turning a subjective and emotional information of one verbal text into quantitative information, from one analysis of temporality as a constitutive element of emotion. It gives us coordinates for a graphic that represents the variation of tension in the text sentence by sentence. It supports simultaneously the representation of prosodic information, such as speech rate in absolute values and, in relative values, the deviation of the duration of speech segments according to the expected patterns. In this paper we present the linguistic basis for this analysis, from a hierarchy of the sense of temporality to the graphics of the modulation of the deep temporal flow.
\end{abstract}

No campo da fonoestilística, mais especificamente nas pesquisas sobre a expressão da emoção na fala, recentíssimos e ainda raros trabalhos buscam alternativas ao método corrente de correlacionar diretamente palavras que designam emoções a características prosódico-acústicas do som de fala. Esse método permitiu a evolução das pesquisas até o patamar atual, com inegáveis conquistas, mas encontra-se hoje numa situação estacionária, com poucas contribuições reais à pesquisa em fonoestilística. $\mathrm{O}$ trabalho aqui apresentado resulta de uma pesquisa iniciada em 1998 no intuito de investigar uma nova abordagem do problema.

A novidade consiste no casamento entre a semiótica e a fonética lingüística, a fim de prover a esta última um conceito mais abstrato de emoção do que aquele calcado no léxico, tratando a emoção como uma linguagem baseada na perturbação dos padrões prosódicofonéticos da fala. Para a fonética e a fonologia, trata-se de trabalhar estatisticamente com a variação da produção em relação aos padrões esperados. Para a semiótica, trata-se de investigar os elementos do conteúdo do texto capazes de indicar orientação e grau de uma variação de tensão interna, correspondente a uma perturbação corporal perceptível - no caso, na fala -, conforme a definição greimasiana de emoção (Greimas \& Fontanille, 1993). O presente trabalho focaliza especificamente os elementos temporais do plano do conteúdo.

*Apoio: FAPESP. 
MATTE - Análise quantitativa da tensividade...

A expressão da emoção na fala é um sistema que opera concomitantemente ao sistema verbal, usando o mesmo instrumento: o trato vocal. O sistema verbal é um sistema sígnico, que correlaciona arbitrariamente significados e significantes (Saussure, 1989, e Hjesmlev, 1968). Trabalhamos com a hipótese de que o sistema da emoção na voz, diferentemente, seja um sistema semi-simbólico, que correlaciona categorias de significantes com categorias de significados (Greimas \& Courtés, sem data). Em outras palavras, trata-se de correlacionar um eixo semântico orientado e contínuo, como a acategoria relaxado/tenso, a um tipo de variação sonora determinada, como, por exemplo, a maior ou menor duração dos segmentos fônicos.

O trabalho com o conteúdo visa focalizar a composição semântico-semiótica das emoções no nível profundo, o mais abstrato segundo a semiótica, antes que sua configuração superficial, mais próxima do léxico. Trabalhar com os componentes da emoção (como proposto por Greimas \& Fontanille, 1993, em especial às páginas 164-170 e 240-241) é vantojoso em relação ao trabalho com tipologias psicológicas, recorrentes na área, porque permite avaliar com um único instrumental a expressão da emoção em diferentes linguagens. Nosso trabalho atual focaliza o português do Brasil (PB) o que, em função dessa característica, não constituiria restrição alguma para sua aplicação em outras línguas.

Nossas pesquisas até o presente momento levaram à categoria da temporalidade no plano do conteúdo como um dos principais componentes do sistema geral de expressão da emoção, não só na fala, como também nos gestos corporais. Apesar do inevitável conflito de nomenclatura, optamos por manter o jargão próprio a cada teoria antes que propor vocábulos alternativos que evitassem o conflito, pois é importante nesse estágio da pesquisa que as referências dentro de cada um dos campos do conhecimento envolvidos continuem explícitas. Para tentar minimizar o conflito de nomenclatura, procuramos indicar em notas de rodapé as expressões semióticas que podem ser confundidas com expressões da fonética em função da homonímia. Como dito acima, a temporalidade no presente texto refere-se exclusivamente ao plano do conteúdo, portanto, no sentido semiótico.

\section{ÁRVORE GERATIVA DA TEMPORALIDADE}

Baseados em Zilberberg (1990) e Fontanille \& Zilberberg (2001), formulamos uma hierarquia da geração do tempo na linguagem a fim de propiciar um instrumental capaz de transformar os componentes temporais da emoção em gráficos da variação da tensão no decorrer da narrativa. A hierarquia está representada pela árvore da figura $1^{1}$ :

${ }^{1}$ Uma análise prática que exemplifica o uso dessa arvore gerativa da temporalidade é apresentada em Matte, 2004. 


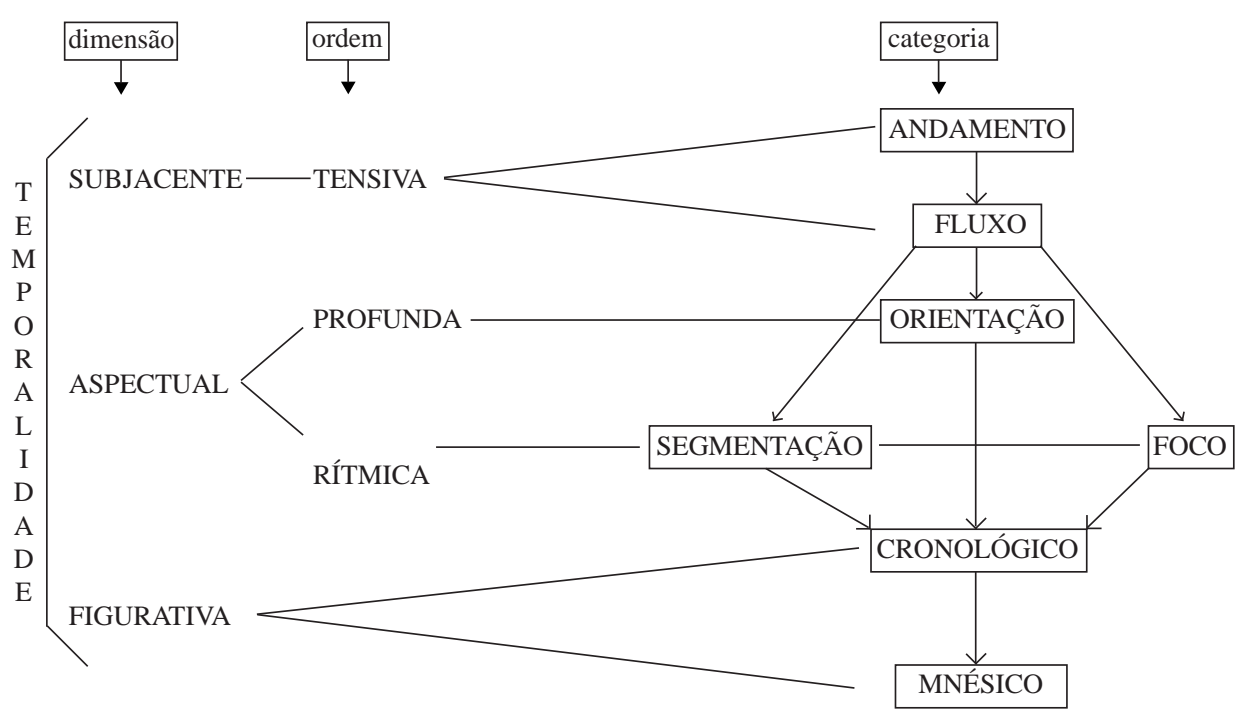

FIGURA 1: hierarquia gerativa da temporalidade no texto.

Cada retângulo corresponde a uma oposição semântica que pode ser analisada em cada sentença segundo a posição que ocupa num percurso do positivo ao negativo do eixo categórico, conforme as diretrizes do quadrado semiótico. Por exemplo, a categoria do andamento corresponde à oposição acelerado/desacelerado, representada no quadrado semiótico da figura 2 :

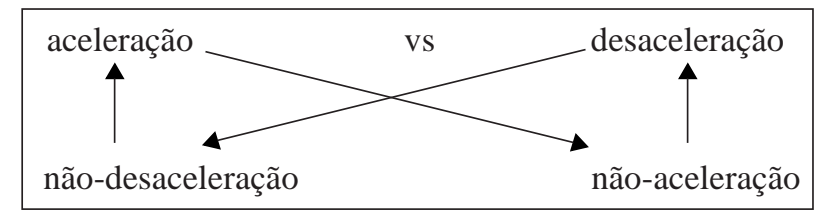

FIGURA 2: Quadrado semiótico da categoria Andamento.

Uma sentença qualquer pode ser acelerada, tender à desaceleração (não aceleração), ser desacelerada ou tender à desaceleração (não desaceleração). Segundo a árvore da figura 1, a geração do tempo segue uma hierarquização de categorias com uma única tripartição: toda sentença pode ser avaliada pela temporalidade tensiva que integra: (i) o andamento (aceleração/desaceleração) e o fluxo (parada/continuação), ambos pertencentes à dimensão subjacente de ordem tensiva; (ii) na dimensão aspectual ${ }^{2}$ a orientação (prospectividade/

${ }^{2} \mathrm{~A}$ aspectualidade é tomada no sentido semiótico, como dinâmica do tempo, do espaço e da pessoa segundo o ponto de viste de um observador interno ao discurso. 
MATTE - Análise quantitativa da tensividade...

retrospectividade) ou a segmentação (gradação/salto) ou o foco (duração/pontualidade), sendo a primeira de ordem profunda da aspectualização e as outras duas de ordem rítmica, e (iii) a temporalidade cronológica (antes/depois) e a temporalidade mnésica (passado/ futuro), ambas elementos figurativos do nível discursivo ${ }^{3}$.

O agora (cronológico) e o presente (mnésico) foram, nas análises de corpora, sempre orientados, em oposição à sua teórica posição neutra (agora = nem depois nem antes, presente $=$ nem passado nem futuro). Em outras palavras, o agora sempre apareceu com uma tendência seja para antes (não-depois), seja para depois (não-antes), assim como o presente sempre se caracterizou como a negação do passado (então tendendo ao futuro) ou negação do futuro ( e então tendendo ao passado). Isso não implica necessariamente na inexistência do termo neutro, mas parece que essa orientação acaba sobredeterminando a figura do neutro (agora e presente). A própria concepção de tempo como algo fluido e incontrolável aparece fortalecida por essa sugestão.

Cada sentença do texto, portanto, receberia cinco designações temporais: duas subjacentes, uma aspectual e duas figurativas. $\mathrm{O}$ andamento modula o fluxo, que por sua vez determina uma aspectualização profunda ou rítmica ${ }^{4}$. Por fim, são aspectualizados os elementos figurativos da temporalidade, cronológico e mnésico. A terminologia é baseada nos trabalhos de Claude Zilberberg (1990) sobre temporalidade. A análise segue o caminho oposto da hierarquia. No entanto, para fins de análise da expressão da emoção os elementos figurativos não apresentaram relevância.

Assim, por exemplo, a seqüência abaixo da história Cachinhos de $\operatorname{Ouro}^{5}$ (a menina e os três ursos) fornece elementos para a transformação do qualitativo em quantitativo. A divisão das sentenças respeitou as pausas da fala da locutora:

1. a) Em matéria de alimentação, eles seguiam a última palavra da moda, com dieta balanceada, pratos naturais e as imprescindiveis tigelas, onde eles botavam seu mingau preferido:

b) açaí com granola, nutritivo e saboroso, dava energia pra todo mundo.

2. a) Só não gostavam de mingau quente.

b) Tinham sempre que esperar um pouco, pois se tomassem pelando queimavam a boca.

O enunciado la aparece numa seqüência de enunciados descritivos sobre o modus vivendi dos ursos, na história de Cachinhos de Ouro analisada. Descrição corresponde a andamento desacelerado porque depende da apresentação gradativa da informação que possibilite a assimilação. O fluxo nessa sentença é uma continuação, considerando-se a

\footnotetext{
${ }^{3}$ A árvore é um desenvolvimento da proposta hierárquica de Zilberberg, 1990.

${ }^{4}$ Observe que rítmica aqui não se refere ao ritmo prosódico, mas ao ritmo como conteúdo do texto.

${ }^{5}$ In: Suzana Vieira Conta Alice no País das Maravilhas./ adaptação Fátima Valença, coleção Olha Quem Está Contando, disco nº 01015/3, Ó1995, P1995.
} 
Cadernos de Estudos Lingüísticos 46(1) - Jan./Jun. 2004

seqüência em que se insere. A dimensão aspectual profunda em 1a é notável, em função da conotação prospectiva da expressão "última palavra da moda"; um dado importante na utilização desta informação é que, neste texto, a prospectividade tem valor positivo, eufórico, e portanto relaxado. Em suma: (i) andamento = desaceleração (relaxamento); fluxo $=$ continuação (relaxamento) e (iii) orientação $=$ prospectividade (relaxamento).

$\mathrm{O}$ enunciado $l b$ é analisado da mesma maneira, exceto pela dimensão aspectual, onde a ordem que aparece é rítmica: a segmentação, em função do fenômeno da listagem, caracteriza gradação, a qual é tão relaxada quanto a prospectividade: (i) andamento = desaceleração (relaxamento); fluxo = continuação (relaxamento) e (iii) segmentação = gradação (relaxamento).

O enunciado $2 a$ e o enunciado $2 b$ ainda são descritivos, explicativos, mas opõem-se à descrição positiva que vinha sendo mantida e, portanto, possuem andamento não desacelerado - a quebra não é completa pois o caráter descritivo é mantido. O fluxo é interrompido pela negação, caracterizando uma parada da continuação, retomada em $2 b$ em função da retomada da negativa. $\mathrm{O}$ aspectual em $2 a$ é rítmico, marcado pela pontualidade na categoria do foco; em $2 b$ a duração da categoria do foco aparece como sempre e esperar. Resumindo, em $2 a$ temos (i) andamento = não desaceleração (tende à tensão); (ii) fluxo = parada da continuação (tende à tensão) e (iii) foco = pontualidade (tensão). Finalmente, em $2 b$ temos (i) andamento = não desaceleração (tende à tensão); (ii) fluxo = parada da continuação (tende à tensão) e (iii) foco = duração (relaxamento).

\section{ANÁLISE TENSIVA DO DISCURSO DE CACHINHOS}

Cada texto é caracterizado por um modelo tensivo, que pode ser inverso ou converso no que concerne à relação entre seus elementos extensos e intensos. A tensão é um elemento intenso que, no caso da análise temporal, varia conforme a variação dos elementos temporais profundos e rítmicos. Cabe ressaltar que essa variação de tensividade não significa variação no tipo tensivo do texto: um texto é sempre caracterizado globalmente por um tipo de tensividade, conversa ou inversa nos moldes de Fontanille e Zilberberg (2001, pp. 15-37), ao que estamos propondo acrescentar o limite, dado pela forma da curva. Por exemplo, na figura 3 vemos um gráfico relacionando extensidade e intensidade de maneira conversa ${ }^{6}$ :

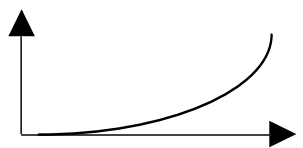

FIGURA 3: gráfico converso com regência da intensidade relacionando o extenso (eixo horizontal) ao intenso (eixo vertical)

${ }^{6}$ Cf. Fontanille \& Zilberberg, 2001, p. 26. 
MATTE - Análise quantitativa da tensividade...

Esse gráfico, que tem no eixo horizontal o extenso e no eixo vertical o extenso, figurativiza a relação entre esses valores no texto, nesse caso uma relação conversa, como se pode ver pela linha diagonal ascendente, na qual o intenso aumenta na medida em que o extenso aumenta.

Propomos acrescentar ao modelo a importância do tipo de curva: a curva conversa poderia ser regida pela intensidade, com limite na extensidade (figura 4) ou regida pela extensidade, com limite na intensidade (figura 3); ambos os exemplos são de modelos conversos:

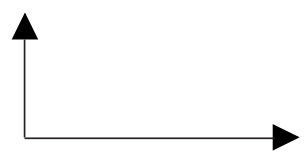

FIGURA 4: gráfico converso com regência da extensidade relacionando o extenso (eixo horizontal) ao intenso (eixo vertical)

O texto que tomamos como exemplo apresenta um modelo tensivo converso regido pela intensidade (figura 4): quanto mais extenso, mais intenso, com extensidade ilimitada. Cachinhos de Ouro é um texto cuja principal paixão se desenvolve na dimensão enunciativa. A narrativa basicamente opõe sujeito1 (Ursos) a sujeito2 (Cachinhos) na disputa pelo objeto (casa). Claramente sob a égide de diferentes destinadores, cada um dos actantes vai entrar em conjunção com o objeto em momentos e maneiras diferentes. O único momento em que ambos os actantes se confrontam é aquele em que os ursos encontram a menina dormindo em uma das camas. Ela foge: desiste do objeto? É, talvez quiséssemos descrever sua fuga como uma vitória dos ursos, cuja figura assustadora se constituiu num poder que o sujeito2 não possuía. No entanto, o quadro de valores no qual se insere Cachinhos sujeito2 - e aquele outro no qual se inserem os Ursos - sujeito1 - são tão diferentes que, em última instância, não se trata do mesmo objeto-valor desejado. Pode-se afirmar que não há comunicação entre eles, cada qual imerso em mundos diferentes.

Observemos os sistemas de valores implicados na narrativa: o sistema 1, que diz respeito à relação ursos/casa, e o sistema 2, que refere-se à relação Cachinhos/casa.

No sistema 1, a propriedade individual é definida pelo tamanho numa relação direta: todas as coisas de tamanho pequeno são de uso exclusivo de Ursinho Fininho, todas as coisas de tamanho médio são de uso exclusivo de Urso Discurso e todas as coisas de tamanho grande são de uso exclusivo de Ursão Pimpão:

A casa dos três ursos era super-incrementada, com tudo dividido entre os três e para os três de acordo com os seus tamanhos.

O espaço, por sua vez, era sempre de uso comum: uma só casa, um só quarto, um só estúdio, uma só cozinha. Todos gostavam de ouvir música, todos se alimentavam da mesma coisas e a decoração, como a própria casa, fora idealizada e realizada coletivamente.

A harmonia decorre, nesse ambiente, de um equilíbrio entre a identidade e a diferença. Contudo, pode-se dizer que havia uma hierarquização da identidade sobre a diferença: o pequeno é usado pelo pequeno, o médio pelo médio e o grande pelo grande. 
Observa-se que a diferença somente aparece em objetos de uso, da ordem do fazer: poder comer, poder sentar, poder ouvir música, poder dormir. O actante sujeito1 (ursos) é figurativizado por atores da mesma qualidade e tamanhos diferentes. Mesmo animal, mesmo sexo, mesma casa, mesma comida, mesmos hábitos: identidade. Diferentes indivíduos, diferentes tamanhos, diferentes nomes, diferentes músicas: diferença. Como identidade e diferença são ambos sobredeterminados euforicamente pelo texto, não podem constituirse termos de uma dicotomia do nível fundamental. É a diferença (a regra do tamanho) que garante aos ursos partilharem espaços e costumes sem privilégios para nenhum deles com igualdade de direitos. Em outras palavras, parecer diferente propicia-lhes direitos iguais ao espaço coletivo.

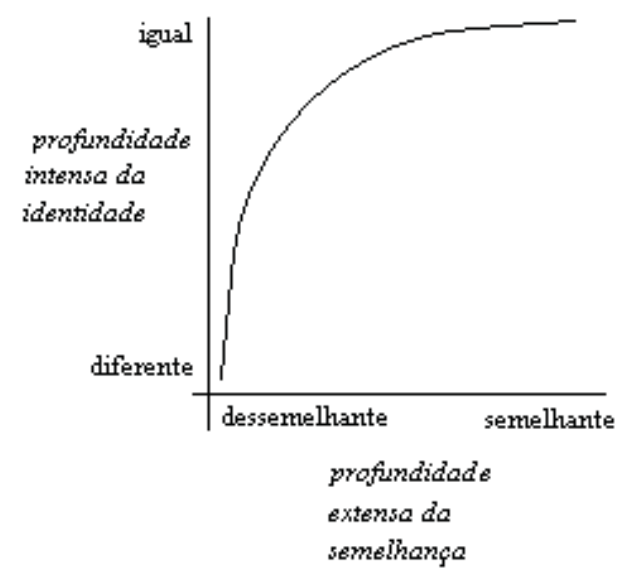

FIGURA 5 - Diagrama da correlação tensiva entre a semelhança e a identidade no sistema 1, o sistema de valores dos ursos.

$\mathrm{O}$ ser-diferente garante uma existência individual, enquanto o parecer-igual garante uma existência coletiva. O coletivo é o espaço, a casa, o quarto, o estúdio; o individual é o tamanho, ou seja, o modo de preencher esse espaço. O espaço é igual, o tamanho é diferente mas faz o modo de preencher o espaço parecer igual. Nesse caso, a dimensão do ser pode ser tomada como um gradiente da profundidade intensa da identidade (igual/ diferente), no qual as forças coesivas residem no igual, enquanto a dimensão do parecer constituiria um gradiente da profundidade extensa da semelhança (semelhante/ dessemelhante, figura 5). Nessa primeira hipótese tensiva, o ser diferente seria sobredeterminado pelo parecer igual e acaba conotando ser-igual.

O sistema de valores 2 , referente a Cachinhos de Ouro, não é especificado no discurso, ou seja, aparece mais pelo não dito do que pelo dito. Cachinhos é diferente porque é um sujeito feminino e humano. Além disso, tem gostos muito específicos, semelhantes ao de Ursinho Fininho, assim como possui gostos menos específicos como os compartilhados pelos ursos (gosta do estilo, não gosta de mingau quente, gosta do tipo do mingau, concorda que haja uma medida certa para cada indivíduo). Desse modo, Cachinhos liga-se a alguns aspectos de dessemelhança e de igualdade aceitos pela coletividade e outros que não são aceitos pela mesma coletividade. 
MATTE - Análise quantitativa da tensividade...

O sistema de valores que rege o fazer dos ursos, sistema 1 , separa objetos exclusivos e objetos partilháveis, sendo que estes últimos pertencem a um sistema fechado de circulação que exclui todo e qualquer sujeito que não pertença a essa coletividade fechada. O primeiro ponto levantado para circunscrever a coletividade é a autoria da construção do objeto.

Assim, o sistema 1 é calcado no respeito à propriedade. Cabe recorrer ao Dicionário Aurélio (Hollanda Ferreira, 1988) (, no qual respeitar é "reconhecer" (definição 6) e "não causar dano a" (definição 5), enquanto propriedade é o "direito de usar, gozar e dispor de bens e de reavê-los do poder de quem quer que injustamente os possua". O sujeito enquadrado nessas regras tolera o não-poder: ele só poderá usar aquilo que lhe pertença e, portanto, não pode usar o que não lhe pertence. Esse texto constrói o lugar da propriedade, "direito legítimo" (definição 4), com duas regras básicas:

- $\quad$ objeto coletivo pertence a quem o construiu: todos os objetos coletivos foram idealizados e realizados pelo actante coletivo (sujeito1) e são de uso coletivo exclusivo de sujeito1 (ursos);

- objeto individual pertence ao ator cujo tamanho é definido pelo mesmo grau da escala de tamanhos fornecida pelo texto (grande, médio, pequeno).

As qualidades dos objetos, se de outra natureza, corroboram a construção das identidades dos indivíduos, fortalecendo as diferenças entre eles, mas essas outras qualidades (macio, duro, alto, etc.) só aparecem na avaliação de Cachinhos: somente o tamanho tem valor no sistema 1 .

No nível narrativo, a junção permitida pelo destinador (valores sociais do respeito à propriedade) sempre será 1 . O sujeito1 será figurativizado pelos ursos coletiva ou individualmente; o objeto abrange tanto objetos coletivos quanto individuais. A diferença coletivo/individual, portanto, aparece no nível discursivo, mas pode ser relacionada ao nível do parecer e à profundidade extensa da semelhança: o diverso é individual, o semelhante é coletivo (figura 6).

O sujeito2 sempre será figurativizado por Cachinhos, portanto sempre um indivíduo, sempre um não-coletivo. Cachinhos é anti-S porque lhe falta direito legítimo: ela não idealizou nem realizou os objetos, ou seja, não participou do percurso de construção do objeto (casa) nem do percurso pressuposto por ele, percurso de obtenção do objeto modal "trabalhar para poder comprar o material"; tampouco era um urso que pudesse entrar na escala de ursos pequenos, médios ou grandes. 


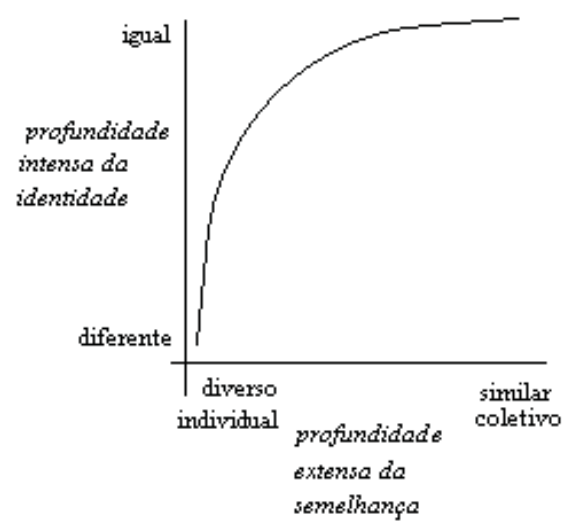

FIGURA 6: diagrama tensivo do sistema 1. Note, em relação ao diagrama anterior, que a extensidade da semelhança é agora sobredeterminada pela relação entre individualidade e coletividade.

Do ponto de vista do sistema 1, o sujeito2 é um sujeito marcado por um dever-nãofazer. A moralização negativa do fazer de Cachinhos pelo narrador recai exatamente sobre esse ponto.

Todos os atores que participaram figurativamente do percurso de obtenção do objeto tem legitimado seu direito sobre ele. Desses atores, somente os que efetivamente entram em conjunção com o objeto tornam-se sujeito1. Pelo contrário, todos os atores que não participaram da construção do objeto estão excluídos da regra de direito legítimo imposta pelo destinador do sistema 1. No entanto, só ocupará narrativamente a posição de sujeito2 aquele sujeito que, desrespeitando a regra, entrar em conjunção com esse objeto.

Além disso, à regra do direito legítimo devemos acrescentar outra, pois esse texto explora por duas vias o respeito à propriedade: por um lado, a legitimidade do proprietário; por outro, o cuidado com a propriedade, pois respeitar é também "não causar dano a" (definição 5 do dicionário Aurélio). Essa segunda regra aplica-se a todo e qualquer ator e, no nível narrativo, será outro constituinte do actante sujeito2. Podemos chamá-la de regra de preservação.

A regra do direito legítimo é uma regra da incoatividade, enquanto a regra de preservação é uma regra de duratividade. O desrespeito a alguma das duas regras seria caracterizado pela terminatividade.

Para o sujeito1, a regra de manutenção tem um caráter retroativo, pois é uma reativação do valor moralizado da incoatividade, a euforia da construção do objeto, vitalizada pela preservação do objeto construído, a regra de preservação revalidando constantemente a regra do direito legítimo.

Para os atores desprovidos do direito legítimo, o cumprimento da regra de preservação absorveria a definição 4 fornecida pelo Aurélio para a palavra "respeitar": "seguir as determinações de, cumprir, observar, acatar". Ou seja, é o caso em que aceitar um sistema de valores afasta proto-sujeitos do devir que os tornaria sujeitos, ou ainda, aceitar os valores impostos pelo destinador do sistema1 implica em desaparecer da narrativa. 
MATTE - Análise quantitativa da tensividade...

Nesse quadro, o fazer do sujeito2 deve ser analisado conforme sua posição no sistema 1. Caso o texto explicitasse um destinador do sistema 2 cuja influência criasse um sujeito2 na conjunção com um objeto exclusivo pertencente a outrém, poder-se-ia falar, por exemplo, em desobediência civil. Mas não é esse o caso.

No entanto, a ausência de figurativização o destinador do sistema 2, ou seja, a não concretização discursiva dessa figura pressuposta pela narrativa, ligada à ênfase dada pelo narrador aos valores do destinador do sistema 1, a quem o narrador em si corporifica com sua voz e enuncia em seus comentários moralizantes, tiram dos ombros de Cachinhos a responsabilidade moral por seu fazer "desrespeitoso".

Cachinhos parece agir sem consciência, parece ou um ser patologicamente destinado a agir na posição de sujeito2 ou um ser imaturo, sujeito volitivo incapaz de ações deônticas. Essa oposição entre o volitivo e o deôntico serão enquadradas na profundidade intensa da identidade: o igual será modalizado por um dever-ser, enquanto o diferente será modalizado por um querer-ser (figura 7).

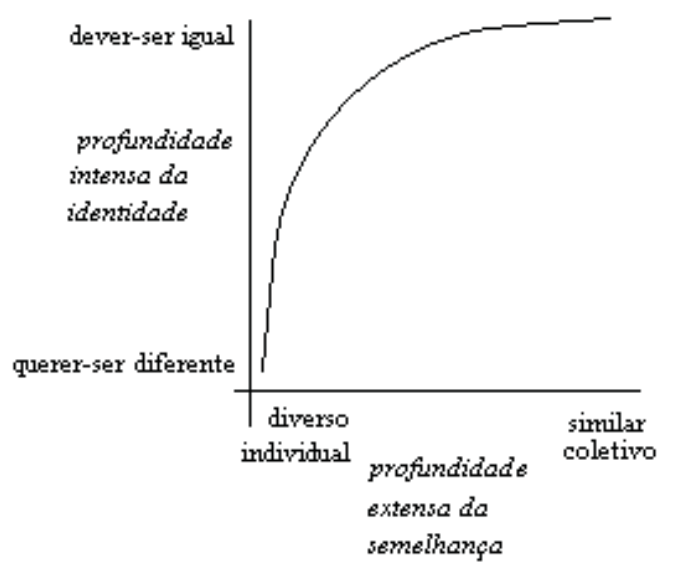

FIGURA 7: diagrama tensivo do sistema 1: a novidade em relação aos diagramas antegriores é a definição modal da profundidade intensa, sendo o mínimo de identidade da ordem do volitivo (querer) e o máximo de identidade da ordem do deôntico (dever).

\section{DO QUALITATIVO AO QUANTITATIVO}

Para fins de transformar os resultados qualitativos da análise tensiva do discurso em números (resultados quantitativos), aliou-se a análise das sentenças segundo a árvore gerativa da temporalidade ao modelo tensivo do texto, exemplificado no tópico anterior.

A análise lógica das relações de dependência hierárquica dos elementos temporais pertinentes sob a égide do modelo tensivo resultou em uma fórmula que permite transformar a informação semio-lingüística em coordenadas em um gráfico da variação da tensão no texto.

A fórmula 1 foi obtida para relacionar esses elementos de temporalidade do texto em textos de tensividade conversa regida pela intensidade. 


$$
\mathbf{M}=\alpha \mathbf{f}-\mathbf{8} \alpha^{1 / \mathrm{n}}+\underline{\mathrm{A}-1}+\mathbf{8} \alpha
$$

A

\section{FÓRMULA 1}

$\mathrm{Na}$ fórmula 1 a constante adotada (8) tem a única função de amplificar as diferenças entre diferentes configurações tensivas (ajuste de escala), num gráfico que permite a colocação de valores de taxa de elocução e de variação da duração de segmentos relativa à faixa de normalidade para cada tipo de segmento no PB. Cabe notar que essa variação contínua de uma variável ao longo dos enunciados (representada por meio de um gráfico da posição no texto vs. variável), é compatível com trabalhos de prosódia do português do Brasil que visam ao modelamento, como em Barbosa (1996, 2000).

A função que procede à modulação da tensividade nos textos (fórmula 1) segue os seguintes princípios básicos:

a) f é o fluxo temporal profundo. Principal elemento tensivo, pois apresenta a dinâmica geral do texto de continuações e paradas, que será modulada por outros elementos dinâmicos, sejam eles o andamento, que tal como o fluxo pertence ao nível fundamental, e a temporalidade aspectual, que pertence ao nível discursivo. Como o fluxo é o elemento de maior impacto na curva de tensividade do texto frase a frase, modificamos seus valores arbitrários tendo em vista uma maior diferenciação visual da implicação e da negação:

- $\quad$ para continuação da continuação, $f=1$ (relaxamento)

- $\quad$ para parada da parada, $\mathrm{f}=2$, pois tende à continuação da continuação

- $\quad$ ara parada da continuação, $f=4$, pois tende à continuação da parada

- $\quad$ para continuação da parada, $f=5$ (tensão)

b) $\alpha=$ andamento: influencia o fluxo temporal profundo e é o principal elemento de determinação do tipo tensivo do texto. Nos textos de tensividade conversa, a relação entre a intensidade e a extensidade do andamento é direta, portanto quanto maior o número de enunciados em sequiências de mesmo andamento, maior o efeito gradual do andamento sobre o fluxo, relaxando-o no caso da desaceleração e tensionando-o no caso da aceleração. Nos textos de tensividade inversa teremos exatamente o efeito contrário. Os valores dados à aceleração e à desaceleração foram também modificados para atender à nova função:

- $\quad$ aceleração: $\alpha=1,10$

- não-desaceleração: $\alpha=1,05$

- não-aceleração: $\alpha=0,95$

- desaceleração: $\alpha=0,90$

c) $\mathbf{A}=$ temporalidade aspectual: notou-se que afeta a tensividade se sua posição não é relaxada, por isso foi incluída na função. Para A, a implicação e a negação têm importância secundária para a curva tensiva visual. Foi mantida a coerência com o quadrado semiótico, mas a fim de que a temporalidade aspectual não sobrepujasse 
MATTE - Análise quantitativa da tensividade...

visualmente o efeito do andamento no gráfico, os valores arbitrariamente atribuídos a ela variam apenas de 1 a 3. Outro dado importante é a decisão de desvincular sua influência do tipo tensivo do texto: a tensividade sempre será maior em presença de A mais tenso (valores mais altos), tanto em textos de tensividade conversa quanto de tensividade inversa. A aparente arbitrariedade de tal decisão deve-se ao fato de que a tensividade é um elemento do nível profundo do texto, enquanto a temporalidade aspectual é um elemento do nível discursivo; assim, não haveria efeito do aspectual sobre a modulação tensiva, mas o contrário. Optamos por manter o aspectual na função, no entanto, porque entendemos que a temporalidade aspectual seria um efeito de sentido produzido pela modulação do fluxo temporal profundo e, sendo assim, seria indicativa dessa tensividade. Como foi comentado anteriormente, o aspectual está dividido em três possíveis ocorrências: a prospectividade/retrospectividade (orientação), a gradação/salto (segmentação) e a duração/pontualidade (foco) que receberão valores arbitrários conforme sua posição no quadrado semiótico e, no caso da orientação, conforme a timia. Apresento aqui, por economia de espaço, somente a orientação com retrospectividade disfórica e prospectividade eufórica:

- prospectividade, gradação ou duração: $\mathrm{A}=1$

- não-retrospectividade, não-salto ou não-pontualidade: $\mathrm{A}=1,5$

- não-prospectividade, não-gradação ou não-duração: $\mathrm{A}=2,5$

- retrospectividade, salto ou pontualidade: $\mathrm{A}=3$

d) $n=$ número do enunciado em seqüência de mesmo andamento: este fator afeta somente o andamento e será usado na determinação do tipo tensivo do texto, tal como comentado acima. Quanto maior o n, maior o efeito do andamento sobre o fluxo. Esse elemento será numerado com números inteiros positivos, sem limite, determinado pela análise do texto.

A determinação do tamanho do enunciado dependerá da análise semiótica do texto. Se a análise acústica solicitar uma divisão do enunciado em partes menores, $\mathrm{n}$ dependerá da análise semiótica dos subtrechos: se for mantido o andamento, a subdivisão implicará em aumento de número de enunciados, mas se houver mudança no andamento, isso implicará reinício da contagem de $\mathrm{n}$.

A função obtida para a visualização gráfica da tensividade em textos conversos regidos pela extensidade apresenta, como esperado, relação direta entre a extensidade e a intensidade de $\alpha$ (figura 8). 


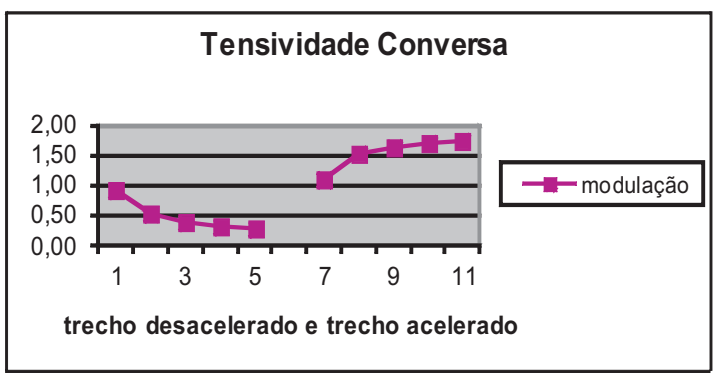

Figura 8: Comportamento da modulação temporal profunda em textos de tensividade conversa com regência da extensidade. No eixo horizontal temos os enunciados enumerados conforme a seïência e no eixo vertical temos os valores da tensão. Em todos os pontos, $\mathrm{f}=1 \mathrm{e} \mathrm{A}=1$. No trecho desacelerado, $\alpha=0,9$ e $n=$ número do enunciado. No trecho acelerado, $\alpha=1,1$ e $\mathrm{n}=$ número do enunciado menos 1 .

À medida em que $\mathrm{n}$ aumenta, aumenta o efeito de $\alpha$ sobre $\mathrm{f}$, como se pode notar no gráfico acima: como desaceleração é relaxamento, no trecho desacelerado enquanto a desaceleração é mantida percebe-se a diminuição da tensão na linha tensiva (ela desce mesmo que todos os parâmetros exceto $\mathrm{n}$ sejam mantidos); como aceleração é tensão, ocorre o oposto no trecho acelerado. Num exemplo de tensividade inversa teríamos uma inversão desse fenômeno.

Com as fórmulas em mãos, o trabalho do analista seria, em primeiro lugar, determinar o tipo tensivo do texto, crucial para determinar a fórmula a ser utilizada. Em segundo lugar, dividir o texto em enunciados e analisar o conteúdo de cada um no que se refere a andamento, fluxo e aspectualização temporal (orientação, segmentação ou foco). Note-se que os elementos temporais figurativos (tempo cronológico e tempo mnésico) foram deixados de lado por sua participação superficial no conteúdo temporal. Finalmente, para visualizar a curva tensiva do texto, o analista precisará unicamente aplicar a fórmula adequada a este texto (conversa ou inversa). A utilidade dessa visualização, no nosso caso, foi contrapor a dinâmica dos dados da expressão à dos dados do conteúdo em gráficos que comportam tanto a informação semiótica quanto qualquer informação de fonética acústica, tal como taxa de elocução ou duração de segmentos.

Para exemplificar, observemos o trecho inicial de Cachinhos $^{7}$, que inicia com uma parada da parada (distensão comum em início de texto) e segue com continuação da continuação (relaxamento) no que concerne ao aspectual. O trecho é todo marcado pela desaceleração (11 enunciados) e pela gradação:

1. a) Era uma vez três ursos que viviam na floresta em uma casa própria de dois andares. Eles mesmos a construíram, ganhando dinheiro com a venda de mel de abelhas. Fabricavam mel com a ajuda das abelhas no terreno que havia nos fundos da casa e vendiam para diversas lojas de produtos naturais. Eles compraram tijolo por tijolo e construíram uma casa com o que havia de melhor em material de obra e de decoração.

\footnotetext{
${ }^{7}$ Versão gravada em disco por uma locutora profissional brasileira para o público infantil.
} 
MATTE - Análise quantitativa da tensividade...

2. a) Eram três ursos muito simpáticos.

b) Um deles era pequeno,

c) o outro era do tamanho médio

d) e o outro era grande.

3. a) O pequeno chamava-se Ursinho Fininho porque era o menor de todos e não era tão gordinho quanto os outros.

4. a) O médio chamava-se Urso Discurso porque, no tempo de colégio, quando alguém tinha que fazer alguma reclamação em nome da turma, era ele quem sempre tomava a frente.

5. a) O grande chamava-se Ursão Pimpão porque, além de ser grandão, gostava de se arrumar e passear na floresta todo pimpão.

6. a) A casa dos três Ursos era super incrementada.

b) Com tudo dividido entre os três e para os três de acordo com os seus tamanhos.

c) Na sala principal, além dos móveis e das peles de ursos herdadas de parentes, havia três cadeiras coloridíssimas, com estamparias de muito bom gosto, em três tamanhos:

d) a cadeira grande para Ursão Pimpão, a cadeira média para Urso Discurso e a cadeira pequena para Ursinho Fininho.

Todos os gráficos apresentam no eixo horizontal a sequiência de enunciados. A linha tensiva deste trecho é descendente, pois a desaceleração relaxa o fluxo mais e mais à medida em que aumenta o número do enunciado na seqüência de mesmo andamento (figura 9).

O pequeno salto descendente notado no início da linha da figura 9 deve-se à mudança do trecho de parada da parada para a seqüência de continuação da continuação.

Observemos agora o mesmo gráfico em relação aos outros elementos do conteúdo, como aparece na figura 10.

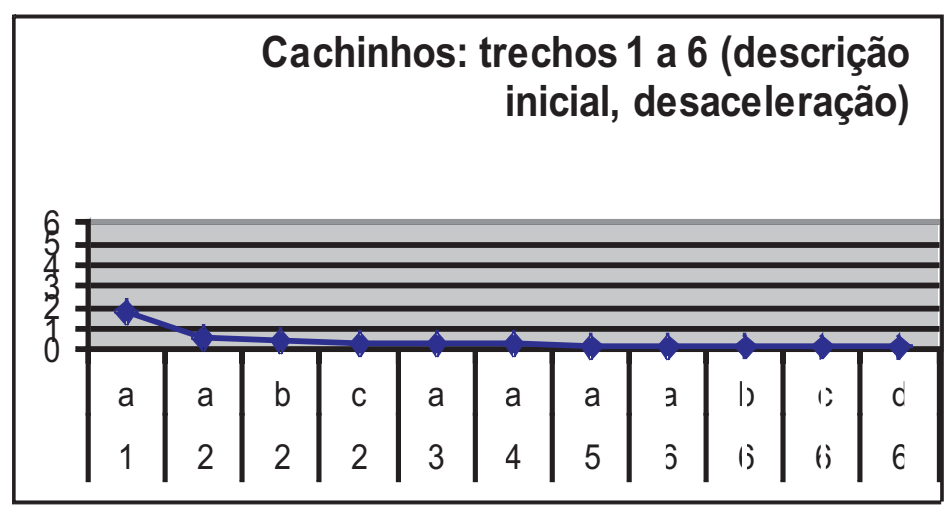

Figura 9: Modulação temporal tensiva vs. enunciados. 
Cadernos de Estudos Lingüísticos 46(1) - Jan./Jun. 2004

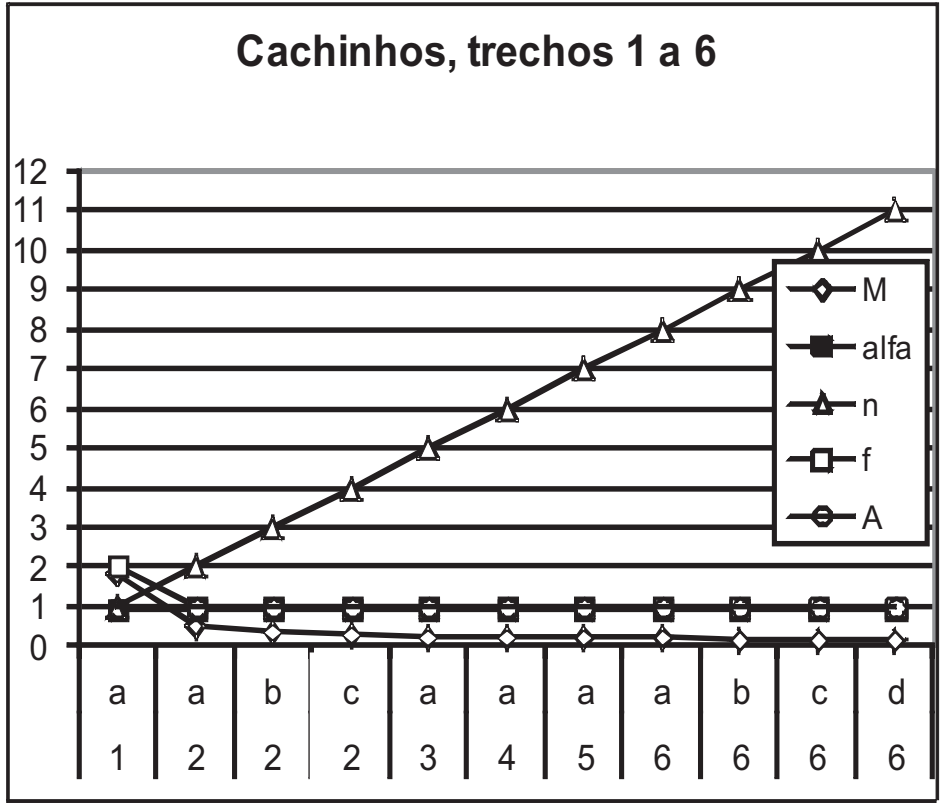

Figura 11: Modulação temporal profunda e seus componentes, enunciados no eixo vertical e valores no eixo vertical.

O andamento $(\alpha)$ é constante, assim como o aspectual (A); em outras palavras, todos os enunciados são marcados por desaceleração e gradação. Em virtude da repetição do andamento, $\mathrm{n}$ aumenta em linha reta, enquanto o efeito da desaceleração vai acentuandose sobre a linha da modulação, cada vez mais próxima de zero. Isso porque o fluxo só é um pouco mais tenso no primeiro enunciado (valor de $\mathrm{f}=2$ ), uma parada da parada típica de enunciados que iniciam textos; depois ele sempre será relaxado (valor de $\mathrm{f}=1$ ).

Observemos os trechos que se seguem, 7a a 11b:

7. a) No segundo andar, junto ao quarto de dormir, os três ursos mandaram instalar um estúdio para ouvir música e relaxar.

b) O estúdio era todo equipado e preparado especialmente para não se ouvir barulho lá de fora, de maneira que todos pudessem curtir o som em paz.

8. a) Como sempre, o tamanho de tudo seguia o tamanho dos ursos.

b) Até mesmo os CDs. Havia três aparelhos de CDs, um pra cada um; o pequeno CD era pra Ursinho Fininho, o CD médio pra Urso Discurso e o CD grande para Ursão Pimpão.

9. a) É claro que cada um também tinha uma cama pra dormir, a cama pequena para o pequeno, a média para o médio e a grande para o grande.

10. a) Em matéria de alimentação, eles seguiam a última palavra da moda, com dieta balanceada, pratos naturais e as imprescindiveis tigelas, onde eles botavam seu mingau preferido:

c) açaí com granola, nutritivo e saboroso, dava energia pra todo mundo. 
MATTE - Análise quantitativa da tensividade...

11. a) Só não gostavam de mingau quente.

c) Tinham sempre que esperar um pouco, pois se tomassem pelando queimavam a boca.

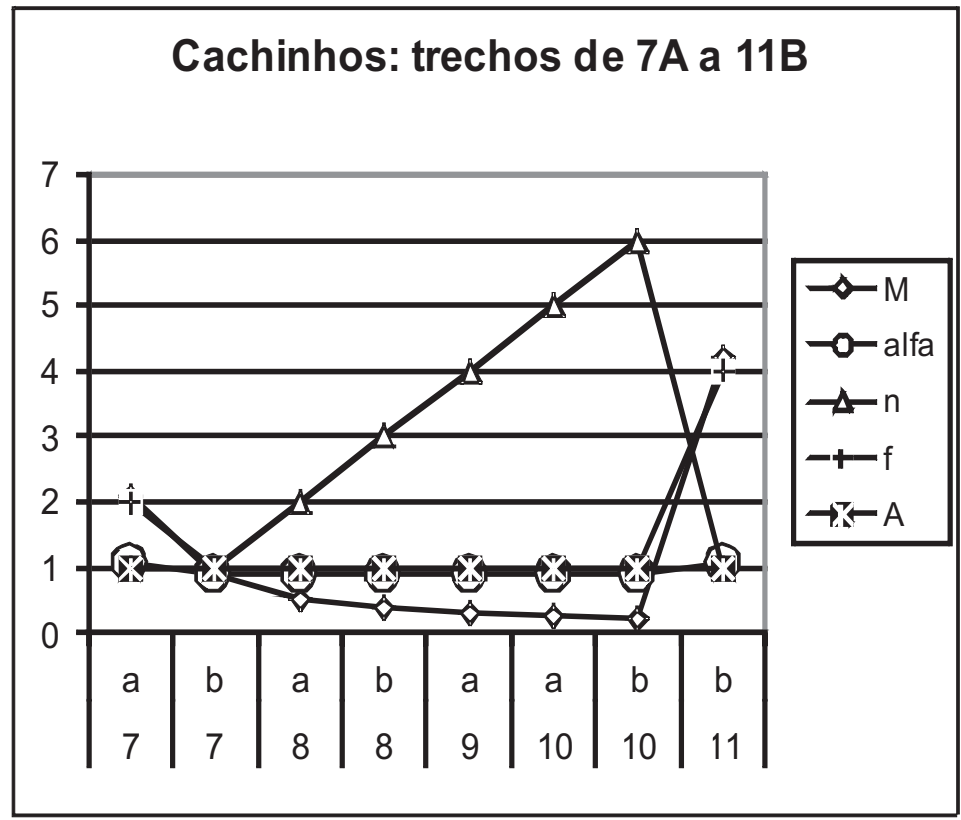

Figura 12: Modulação temporal profunda nos trechos 7a a 11b. Discrimina componentes de M no eixo vertical e enunciados no eixo horizontal.

Esses trechos (7a a 11b, figura 12) apresentam variação de f, (parada da parada em $7 \mathrm{a}$, passa a continuação da continuação em $7 \mathrm{~b}$ e a parada da continuação em 11b), de $\alpha$ (não-desacelerado em $7 \mathrm{a}$, passa a desacelerado em $7 \mathrm{~b}$ e retorna a não-desacelerado em 11b). Apesar de haver uma mudança no aspectual, a tensividade permanece relaxada: gradação e prospectividade são elementos aspectuais relaxados nesse texto e têm o mesmo valor 1. O gráfico da figura 12ilustra essas relações.

Pode-se perceber o efeito do aumento de $\mathrm{n}$ acentuando o efeito de $\alpha$ sobre $\mathrm{f}$ nos trechos $7 \mathrm{~b}$ a 10b (por enquanto omitimos os trechos não passíveis de análise acústica, tais como 11a) (figura 12). Além disso, a não-desaceleração provoca uma elevação da linha de modulação em relação ao fluxo (7a e 11b), contrariamente ao que ocorre se o andamento é desacelerado (7b a 10b). Não há qualquer influência do aspectual, como esperado pela análise semiótica que vinculou prospectividade eufórica e gradação aos trechos analisados. 


\section{CONCLUSÃO}

Os gráficos aqui propostos permitem verificar, por exemplo, a relação entre a variação da modulação temporal tensiva do texto, que é um componente profundo e abstrato da emoção, e a variação da taxa de elocução ou os desvios da duração dos segmentos conforme o padrão esperado. Observou-se no corpora utilizado uma relação direta e quase sentença a sentença entre a taxa de elocução e a modulação do fluxo temporal profundo. Também notou-se, ao focalizar no plano da expressão os desvios da duração dos segmentos vogala-vogal em relação ao padrão esperado para o português do Brasil, uma grande influência do comportamento tensivo do texto dividido em partes conforme a narrativa.

Essa fórmula indica a possibilidade de transformar a informação subjetiva do texto em informação objetiva e, portanto, passível de processamento computacional. Dessa forma, indica uma via para o tratamento da expressão da emoção na voz pelo modelamento prosódico não só para o português do Brasil, foco da nossa pesquisa, como também de qualquer outra língua.

\section{REFERÊNCIAS BIBLIOGRÁFICAS}

BARBOSA, P.A. (1996). At Least two macrorhytmic units are necessary for modeling Brazilian Portuguese duration: emphasis on segmental duration generation. Cadernos de Estudos Lingüísticos, 31, pp. 33-53. . (2000). "Syllable-timing in Brazilian-Portuguese": uma crítica a Roy Major. Revista Delta vol. 16, n² 2 , pp. 369-402.

FONTANILlE, J. \& ZILBERBERG, C. (2001). Tensão e Significação/ trad. Ivã Carlos Lopes, Luiz Tatit e Waldir Beividas. - São Paulo: Discurso Editorial: Humanitas/FFLCH/USP.

GREIMAS, A.J. \& COURTÉS, J. (sem data). Dicionário de Semiótical trad. Alceu Dias Limas, Diana Luz Pessoa de Barros, Eduardo Peñuela Cañizal, Edward Lopes, Ignácio Assis da Silva, Maria José Castagnetti Sembra e Tieko Yamaguchi Miyazaki. São Paulo, Ed. Cultrix.

GREIMAS, A.J. \& FONTANILLE, J. (1993). Semiótica das Paixões - dos estados de coisas aos estados de alma./trad. Maria José Rodrigues Coracini. Série Temas \# 33. São Paulo, Ed. Ática.

HJELMSLEV, L. (1968). Prolégomènes a une Théorie du Langage - et - La Structure Fondamentale du Langage. /trad. Anne-Marie Léonard. Série Arguments \# 35. Paris, Les Editions De Minuit.

HOLlANDA FERREIRA, A.B. (1988). Dicionário Aurélio Básico da Língua Portuguesa. Rio de Janeiro, Ed. Nova Fronteira.

MATTE, A.C.F. (2004). “Tempo fonoestilístico e semi-simbólico: a árvore gerativa da temporalidade”. Estudos Lingüísticos V. XXXIII. GEL: Campinas, SP, 2004.

SAUSSURE, F. (1989). Cour de linguistique générale./ Ed. critique par Rudolf Engler. Wiesbaden: Harrassowitz.

ZILBERBERG, Cl. (1990). "Relativité du rythme". In Protée-Théories et Pratiques Sémiotiques. Département des Arts et Lettres de 1'Université du Quebec à Chincontimi. Vol. 18, n.o 1, pp. 37-46. 